\title{
Impact of Sediments on Wear Performance of Critical Sliding Components of Hydrokinetic Devices
}

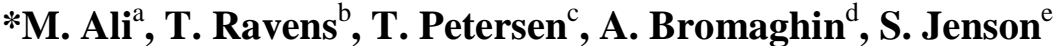 \\ ${ }^{a}$ Associate Professor of Mechanical Engineering, Ohio University, Athens, OH, USA, \\ Ph: 740-593-1389, Email: alim1@ohio.edu \\ ${ }^{b}$ Professor of Civil Engineering, University of Alaska, Anchorage, AK, USA \\ ${ }^{c}$ Assistant Professor of Electrical Engineering, University of Alaska, Anchorage, AK, USA \\ ${ }^{d}$ Research Assistant, University of Alaska, AK, USA \\ ${ }^{e}$ Research Assistant, Ohio University, Athens, OH, USA
}

\begin{abstract}
The work discussed here is a continuation of the study presented in [1], in which a customized test apparatus was presented that was capable of conducting tribological related experiments on sliding components commonly used in hydrokinetic devices such as bearings, drive shaft and seals. The wear on critical sliding components introduces unnecessary clearances which can significantly reduce the performance and reliability of hydrokinetic devices. In the previous study [1], four types of bearings, namely Vesconite, CIP, Feroform T814, and Poly Crystalline Diamond (PCD) coated bearings were tested for 60 hours in clean water. The data showed that PCD bearings outperformed polymer based bearings in terms of wear and frictional resistance. In the present study, the same set of bearings were tested for 60 hours in fresh sedimented water. The experimental data revealed that PCD bearings had higher wear resistance as compared to its polymer based counterparts. In addition to wear on bearing surface, a significant amount of wear on the drive shaft was observed. These results reveal that (in addition to high wear resistant polymer bearings) a surface hardened shaft may increase the longevity of bearing-shaft assembly in sedimented water.
\end{abstract}

Keywords: abrasion, wear, sliding, hydrokinetic, friction, power, energy, flume, sediments

\section{Introduction}

With increasing energy demands and diminishing fuel reserves, there is ever increasing demand for sustainable renewable energy methods. Studies show trends of increasing population in coastal areas around the world [2,3], and with these trends comes an increased need for localized reliable and sustainable energy sources. These sources include non-conventional hydrokinetics and ocean energy resources. Hydrokinetic devices have lately shown potential for power generation [4-6], however, important environmental and mechanical issues need to be addressed before these systems are commercialized [7,8]. One of the critical mechanical issues is wear of the bearing-shaft assembly in a typical hydrokinetic device, which has direct effect on device performance and efficiency.

Wear of mechanical components can stem from tribological effects during normal operation and environmental effects such as biofouling and tribocorosion [9-13, 14-16]. Contact pressure, during normal operation, between bearing and shaft causes wear over time. This wear leads to excessive clearances between shaft and bearing (causing inevitable efficiency drop in mechanical operations) and eventual catastrophic failures of other system components such as mechanical seals and the electrical generator. In cases where the device is fully submerged, introduction of sediments between the shaft and bearing surface can cause additional wear that needs to be considered by hydrokinetic device manufacturers. A clear understanding of the impact of sediments on tribological characteristics of bearing-shaft assemblies is needed to select the most wear resistant system in order to lower the frequency of occurrence of expensive infield maintenance of hydrokinetic devices.

Engineering polymers for marine bearing applications are increasing in popularity for a number of desirable characteristics. Polymers have a low manufacturing cost, are lightweight and self-lubricant, and have a higher resistivity to wear and corrosion than most metals. In addition, ceramic coated bearings are gaining some interest for application in hydrokinetic devices [1]. Most investigations on the sliding friction and wear behavior of polymer bearings have been under dry friction with a few under pure water immersion and fewer still in sea water [17-20]. The research on the effects of sediments on tribological characteristics of polymer based and ceramic coated bearings is either non-existent or proprietary. Under this perspective, there is a need for bearing performance data under sedimented water conditions. 
In previous study [1], we investigated the wear characteristics of three types of polymer based bearings and one set of ceramic coated bearings submerged in clean fresh water. Each bearing type was tested for 60 hours. It was concluded that ceramic coated bearings exhibited the least amount of wear and had the lowest value for its coefficient of friction. Furthering that work, this paper focuses on investigating the wear characteristics of (same) polymer based and ceramic coating based bearings (which were selected in previous study) under sedimented water conditions. The results of the present study will provide valuable insight into proper bearing selection for hydrokinetic devices that are going to be deployed in sedimented waters, thus, improving the efficiency of operations with reducing maintenance requirements and downtime.

\section{Experimental Setup and Methods}

\section{Testing Apparatus}

For the present study, a custom test apparatus designed and built in the previous study [1] was used to conduct the tests. The apparatus consisted of a closed flume that included two test stations, inlet and outlet diffusers, water reservoir, paddle flow meter, and a custom built heat exchanger. Figure 1 shows a process diagram of the flume system, and Figure 2 shows the actual flume.

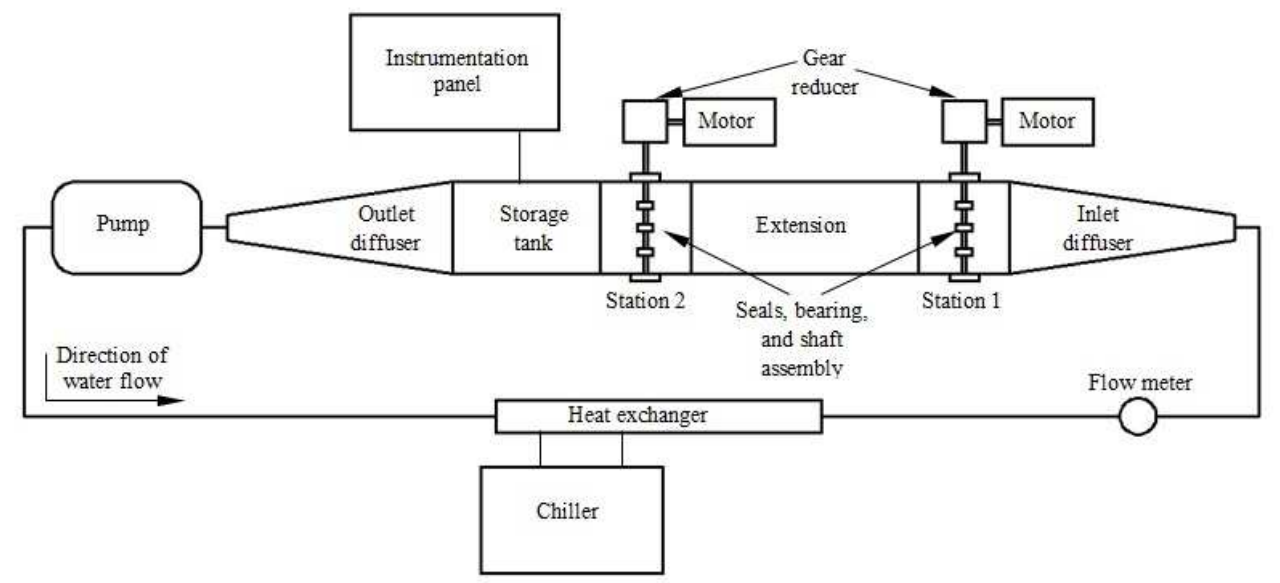

Figure 1: Process flow diagram of the flume apparatus [1]

The bearings were mounted on a shaft through split vertical support mounts, and the entire bearing-shaft assembly was fit into a steel housing. This assembly made up the testing stations 1 and 2, denoted in Figures 1 and 2 . Each test station housed three bearings, which were aligned in a single row and positioned in such a way as to imitate the arrangement of bearings deployed in the field. Figure 3 displays a portion of the cross-section of one of the stations showing arrangement of bearings and seals. The outer bearings were kept close to the center bearing to avoid (shaft) deflection induced wear. The center bearing was mounted in such a way that its horizontal motion was constrained with a limited allowable vertical motion. The two outside bearing supports were bolted on the base of the station and acted as fixed supports when the center bearing was loaded, thus avoiding any transfer of deflection of shaft to the seals. Each of the bearing mounts was equipped with a Resistance Temperature Detector (RTD) to measure the temperature of the bearings during the flume operation. A force of $2250 \mathrm{~N}$ was applied on the middle bearing mount by using a linear hydraulic mechanical actuator. A one horsepower Marathon Electric washdown motor was used to turn the shaft at $300 \mathrm{rpm}$. The shaft speed and applied load developed Pressure-Velocity (PV) values of 74.17 MPa. $\mathrm{m} / \mathrm{min}$ and $37.08 \mathrm{MPa}$. $\mathrm{m} / \mathrm{min}$ on center and side bearings, respectively. An actual size bearing shaft-assembly would undergo these PV values for a tidal current of approximately 6 knots and 3 knots that hydrokinetic devices normally experience. Sedimented water with $1 \mathrm{~g} / \mathrm{L}$ particle concentration was circulated through the flume at a rate of 1136 liters per minute and maintained at a temperature of 7.22 degrees Celsius using the heat exchanger.

There is a wide range of sedimentary conditions in Alaska waters in which hydrokinetic devices could potentially be deployed. In Cook Inlet (by Fire Island), analysis of suspended sediments by team of University of Alaska (and others) found grain sizes ranging from fine silt (10 microns) to fine sand (100 microns). Suspended sediment concentrations up to $600 \mathrm{mg} / \mathrm{L}$ were measured. Similarly, in the Kashunuk River on the Yukon Kuskokwim Delta, 
analysis of samples indicated suspended sediments ranging from fine silt to fine sand (100 microns) and concentrations up to $800 \mathrm{mg} / \mathrm{L}$. A USGS study of suspended sediments in the Yukon River found concentrations up to $1.1 \mathrm{~g} / \mathrm{L}$, with most common mineral in the silt and sand size range being quartz [21]. The study also found concentrations up to $1.6 \mathrm{~g} / \mathrm{L}$ in the Tanana River at Nenana. The water temperatures in Cook Inlet in the proximity of Kenai Peninsula were noted to be within 5 to 11 degrees Celsius in summer [22]. For Yukon River, the temperatures ranged in between 6 to12 degrees Celsius [23]. Given these considerations, the sediment sizes, mineralogy, and concentration tested in the flume were chosen to be representative of the sediments typically seen in Alaska waters where hydrokinetic devices might be deployed. Table 1 lists the sediment size and quantity introduced in the flume.

Table 1: Sediment size and quantity introduced in the flume

109

\begin{tabular}{|c|c|c|}
\hline Sediment type & Grain size & Quantity \\
\hline Yukon bed sample & $\mathrm{d} 50=0.2 \mathrm{~mm}$ (range 0.18mm- 0.25mm) & $90 \mathrm{~g}$ \\
\hline Industrial sample 1 & $\mathrm{d}=0.010 \mathrm{~mm}$ & $40 \mathrm{~g}$ \\
\hline Industrial sample 2 & $\mathrm{d}=0.028 \mathrm{~mm}$ & $50 \mathrm{~g}$ \\
\hline Combined samples & $\mathrm{d} 50=0.07 \mathrm{~mm}$ & $180 \mathrm{~g}$ \\
\hline
\end{tabular}

The concentration of sediments was monitored through a turbidity sensor. The main purpose of utilizing flowing water in the flume was to keep the sediments suspended and create turbulence that would be present in natural setting and would provide a mechanism for sediment intrusion into the bearing parts. Each station was equipped with a Linear Variable Differential Transducer (LVDT) for measuring shaft deflection and bearing wear. In order to prevent sedimented water leaking from test stations, mechanical seals with single contact surface and double contact surfaces were installed. These seals emulated the seals in a hydrokinetic device that exclude water from a submerged generator. Station 1 was used to test polymer bearings and Station 2 was used to test ceramic coated bearings.

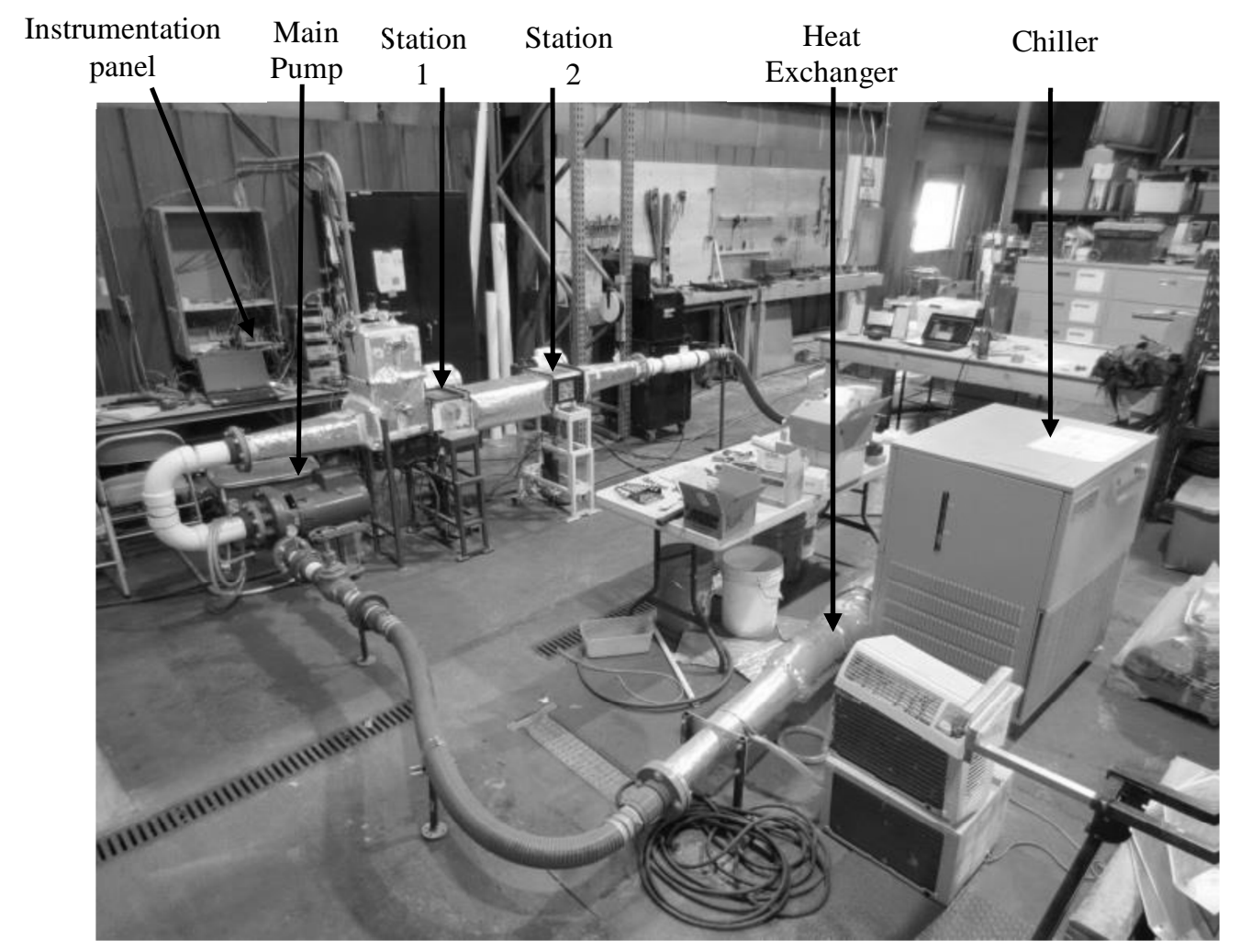

Figure 2: Custom fabricated flume apparatus 


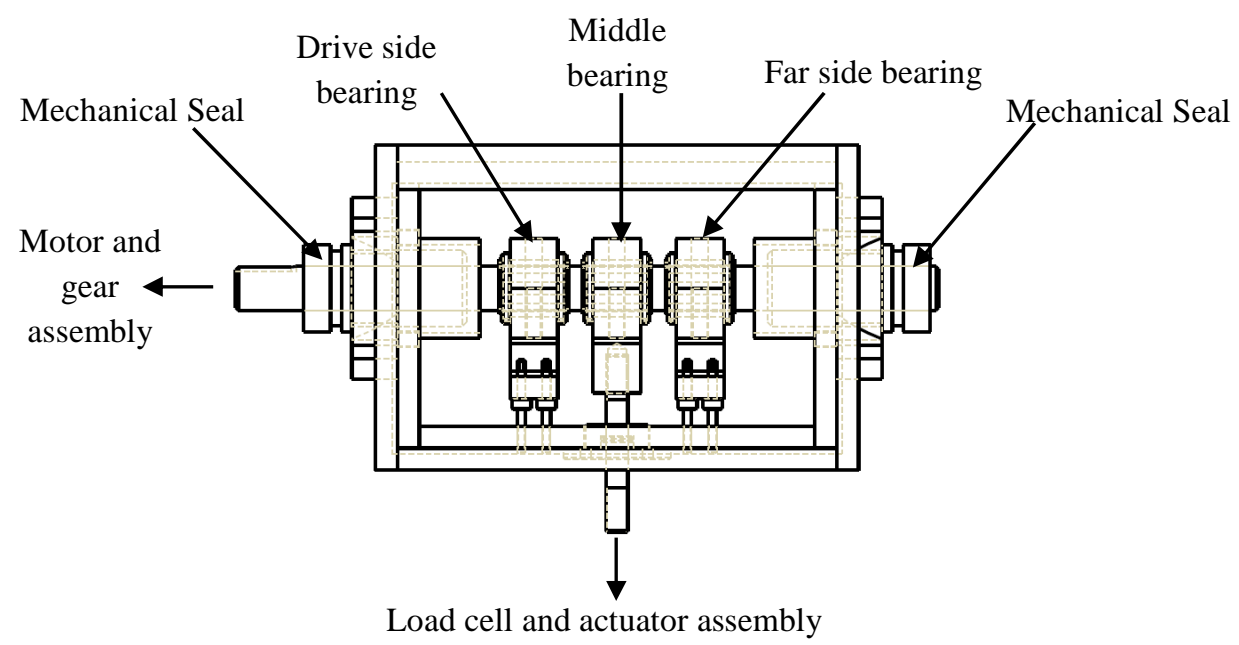

Figure 3: The cross-sectional view of a single station

\section{Bearing Types and Testing Methodology}

For the present study, four bearing types were examined: CIP Marine, Feroform, Vesconite, and steel bushings with polycrystalline diamond inserts (PCD). CIP Marine (CIP) and Feroform bearings were made of composite material consisting of fabric weaves integrated with lubricants. Vesconite was composed of a homogenous, self-lubricating thermoplastic. The fourth material used in this study consisted of a steel bushing with a ring of polycrystalline diamond (PCD) inserts set along its inner face. This bearing was referred to as ceramic coated bearing in previous sections. All four of these materials and bearing designs used in this study are available commercially. The mechanical and thermal properties of the bearings are listed in Table 2 and bearings are shown in Figure 4 . Each bearing type was selected based on recommendations of bearing experts, recommendations of manufacturer's (that the bearing was designed to operate satisfactorily under the test conditions of present study), and interest or experience from hydrokinetic device developers in using bearing type. The bearings were manufactured with a one inch nominal inner diameter which was selected based on ease of design and ability to manufacture. To ensure scalability of the test results, values of bearing pressure and velocity (PV) were chosen that were comparable to that expected in field deployments. The PV value is a widely used industry standard for comparing bearing life expectancies and wear resistance [24].

The Vesconite, CIP Marine, and Feroform T814 bearings were tested using a 16 inch long '316 stainless steel' shaft with an outer diameter of 1 inch. The PCD bearings were tested using a shaft manufactured from 17-4 PH 1150 stainless steel with PCD inserts inset along its outer face and spaced such that the PCD surface on the outside diameter of the shaft were in direct contact with the PCD surface on the inside diameter of the mating bearing as shown in Figure 5. This arrangement allowed rubbing contact between corresponding PCD surfaces during operation. The contact diameter between the PCD inserts on the shaft and bearings was the same as that between the polymer bearings and shaft. Both shafts are shown in Figure 6.

Prior to testing, the inner diameter of each bearing was measured using internal telescoping gauges, a micrometer, and a digital caliper. Each bearing was fitted onto its corresponding shaft and placed in each test station. Once the flume was water filled and tight, the main system pump and chiller were turned on to circulate water at 1136 liters per minute and maintained it at temperature of 7.22 degrees Celsius. Then the electric motor for each station was turned on to rotate the shafts at $300 \mathrm{rpm}$ and a load of $2200 \mathrm{~N}$ was applied to the center bearing in each station. Each test was to last 60 hours to allow sufficient time for measurable wear to occur. Once the testing time of 60 hours passed, the load was removed and the inner diameters of the bearings were measured again using the same methods as the initial measurement. The difference in measurements was related to determine total wear. The LVDT 
mounted on the center bearing link assembly provided necessary data on progressive wear (on center bearing) during the test.

Table 2: Mechanical and thermal properties of candidate bearings

\begin{tabular}{|c|c|c|c|c|}
\hline & Vesconite & CIP & Feroform T814 & PCD \\
\hline Bearing type & Fluted Bushing & Fluted Bushing & Fluted Bushing & $\begin{array}{l}\text { Bushing/Diamond } \\
\text { inserts ring }\end{array}$ \\
\hline Bearing material & $\begin{array}{l}\text { Specialized } \\
\text { thermoplastic } \\
\text { made from } \\
\text { internally } \\
\text { lubricated } \\
\text { polymers }\end{array}$ & $\begin{array}{l}\text { Proprietary blend of } \\
\text { textile, lubrication } \\
\text { and resin mixture } \\
\text { specifically } \\
\text { formulated for the } \\
\text { Marine industry }\end{array}$ & $\begin{array}{l}\text { composite material } \\
\text { made from woven } \\
\text { fiber bonded with } \\
\text { resin with PTFE as a } \\
\text { friction modifier }\end{array}$ & $\begin{array}{l}\text { Diamond grit fused } \\
\text { together under high } \\
\text { pressure, high } \\
\text { temperature in the } \\
\text { presence of a } \\
\text { catalytic metal }\end{array}$ \\
\hline Density (g/cm3) & 1.3 & 1.3 & 1.3 & not available \\
\hline Hardness & Shore D, 84 & Rockwell, 100 & Brinell, 25 & Knoop, 49 \\
\hline $\begin{array}{l}\text { Compressive } \\
\text { strength (MPa) }\end{array}$ & 92 & 103 & 68.9 & 7,000 \\
\hline $\begin{array}{c}\text { Modulus of } \\
\text { Elasticity (MPa) }\end{array}$ & $\begin{array}{l}\text { Tagent, } 3400, \\
\text { compression, } \\
2290\end{array}$ & $\begin{array}{l}\text { Tensile, } 3240 \text {, } \\
\text { flexure, } 1793\end{array}$ & not available & Young's, 841,000 \\
\hline $\begin{array}{c}\text { Operating } \\
\text { temperature }\left({ }^{0} \mathrm{C}\right)\end{array}$ & -40 to 65 & -40 to 93 & 100 & not available \\
\hline $\begin{array}{l}\text { Coefficient of } \\
\text { thermal expansion } \\
\qquad\left({ }^{0} \mathrm{C}^{-1}\right)\end{array}$ & $6 \times 10-5$ & $\begin{array}{c}7.2 \times 10-5 \text { normal to } \\
\text { laminate direction, } \\
3.6 \times 10-5 \text { parallel to } \\
\text { laminate }\end{array}$ & $70 \times 10-6$ & not available \\
\hline $\begin{array}{l}\text { Coefficient of } \\
\text { friction }\end{array}$ & $\begin{array}{l}\text { Dry, Vesconite } \\
\text { on steel, } 0.09 \\
\text { to } 0.1 \\
\end{array}$ & not available & $\begin{array}{l}\text { Dry, } 0.04-0.08, \text { wet, } \\
0.06 \text { to } 0.09\end{array}$ & $\begin{array}{l}\text { Wet, PCD on PCD, } \\
0.05 \text { to } 0.08\end{array}$ \\
\hline
\end{tabular}

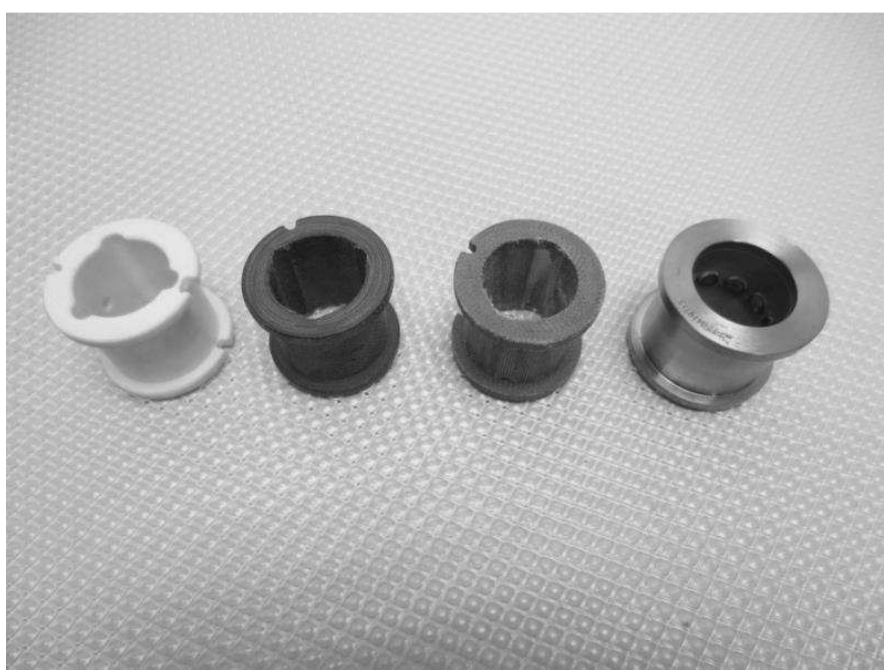

Figure 4: The four candidate bearings tested in this study are shown left to right - Vesconite, CIP Marine, Feroform T814, and Polycrystalline diamond radial bearing. 


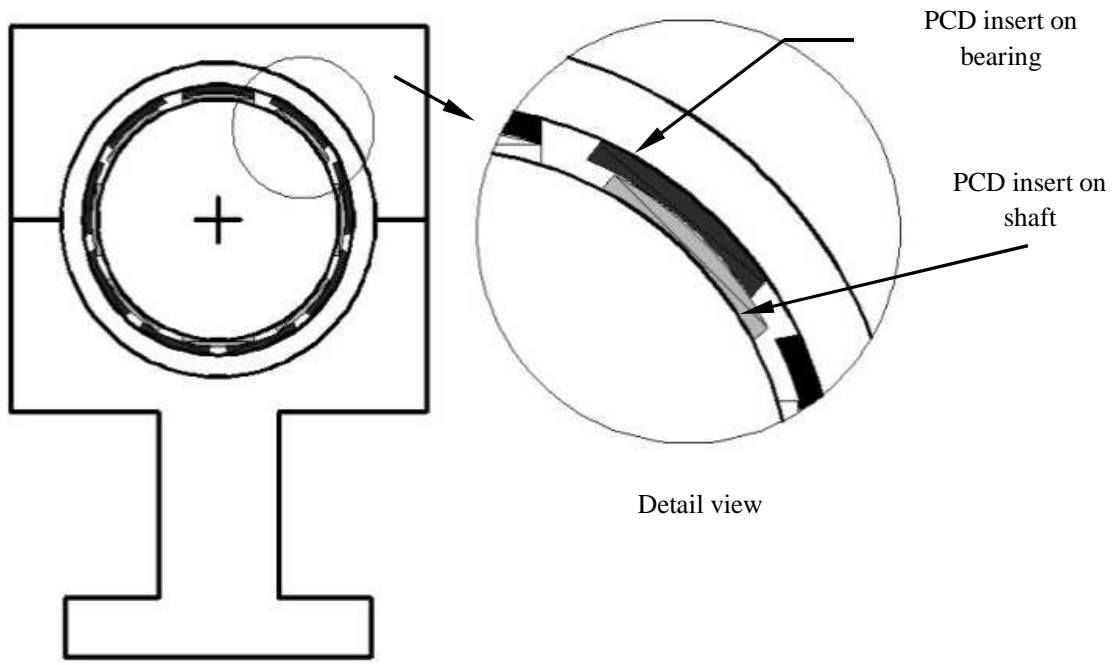

Figure 5: The side view of the PCD bearing mount [1].

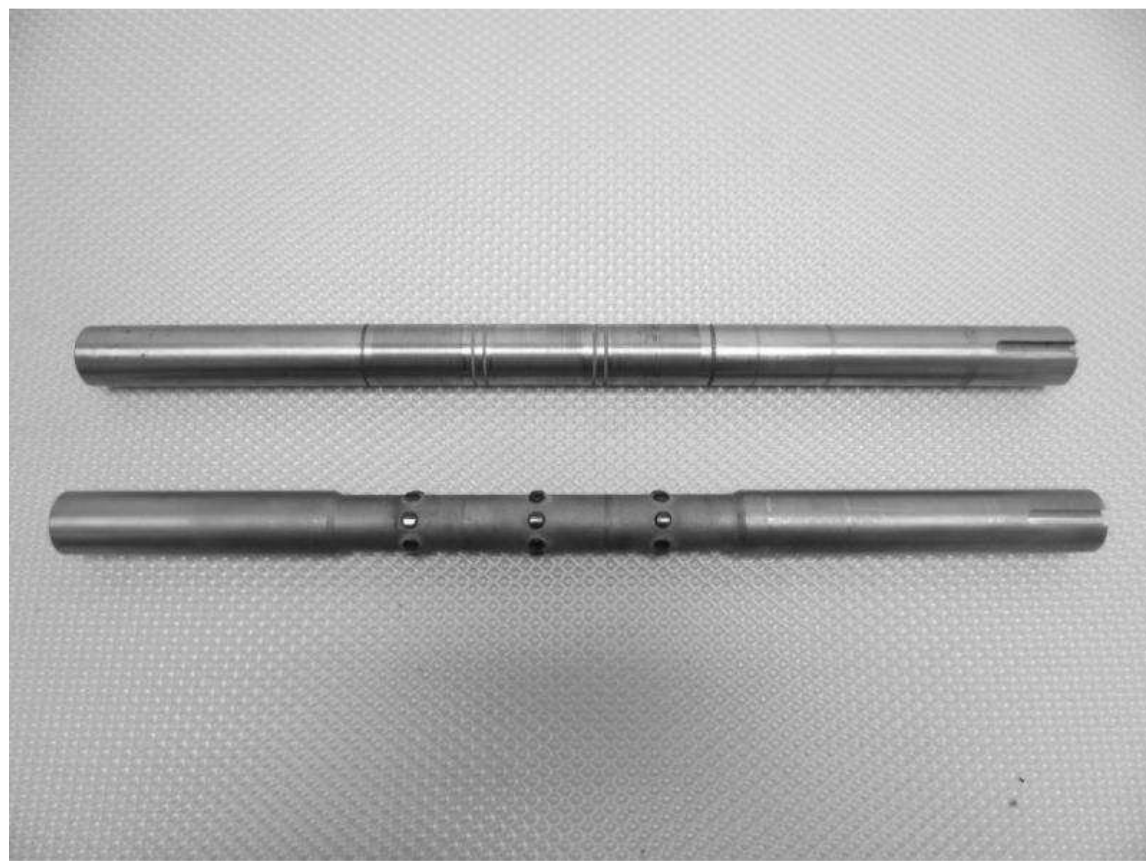

Figure 6: The polymer bearing shaft (top) and the polycrystalline diamond inset shaft (bottom).

The wear on the side bearings is critical as it transfers deflection to the seals. Since LVDT was installed on center bearing, in order to determine combined wear on side bearings and shaft surface (from LVDT data of center bearing), linear wear rate relationships (established in Figure10), after the bearing-shaft surfaces were fully adjusted, were modified. It was assumed that the combined wear pattern (or shape of the wear curve) on side bearings (and shaft surface) was the same as for the center bearing. With this assumption, the ratios of combined wear on center and side bearings (and shaft) were exploited to adjust the curve slopes, and results were extrapolated beyond $60 \mathrm{hrs}$. The maximum acceptable tolerance for mechanical seals used in the present study, as recommended by the manufacturer, was $9.549 \times 10^{-3} \mathrm{~mm}$ per $\mathrm{mm}$ of shaft diameter. 
Since the parasitic energy losses due to bearing friction can have significant effect on the energy extraction efficiency of a hydrokinetic device, it is important to determine the Coefficient Of Friction (COF) of candidate bearings in present study. A method developed in [1] was adopted here, which translated the power data collected at the end of each test to COF. Following the methodology, the COF were estimated by balancing power in the system for each bearing type, which revealed the following equation:

where

$$
\mathrm{P}_{\mathrm{in}}-\mathrm{P}_{\mathrm{misc}}-\mathrm{r} \omega\left[\left(2 \mathrm{~F}_{13} \mu_{13}\right)-\mathrm{F}_{2} \mu_{2}\right]=0
$$

$P_{i n}=$ Total power supplied by the motor to energize the entire drivetrain when center bearing was loaded (watt)

$\mathrm{P}_{\text {misc }}=$ Power consumed to energize the entire drivetrain when center bearing was (mounted on the support and) unloaded. This included power consumed to overcome internal losses in motor, gear box, coupling, seals, and center and far side bearings (watt)

$\mathrm{r}=$ Radius of shaft $(\mathrm{mm})$

$\omega=$ Rotational speed of shaft ( $\mathrm{rad} / \mathrm{s})$

$\mathrm{F}_{13}=$ Reaction load on each side bearing (drive or far side) $(\mathrm{N})$

$\mathrm{F}_{2}=$ Applied load on center bearing $(\mathrm{N})$

$\mu_{13}=\mathrm{COF}$ at side bearing (drive or far side)

$\mu_{2}=\mathrm{COF}$ at center bearing

Due to the tight range of gear-motor system efficiency, constant seal frictional loss, infinitesimal change in the main drive train speed, constant ambient operating temperature, and approximately constant gearbox oil viscosity (due to constant temperature in gearbox as power tests were conducted and completed within a few minutes after the main tests), it was assumed that $\mathrm{P}_{\text {misc }}$ remained relatively constant over the range of the applied loads. Equation 1 has two unknowns; $\mu_{13}$ and $\mu_{2}$. A second equation was generated by assuming linear variation of COF with applied load on the bearing, which gives

$$
\mu=\mathrm{m} * \mathrm{~F}+\mathrm{b}
$$

Where ' $\mathrm{m}$ ' and ' $\mathrm{b}$ ' are slope and offset of a linear curve traced out by Equation 2 . The underlying reason of the above assumption comes from the linear nature of test power curves with respect to applied load for Vesconite and PCD bearings. The power curves for CIP and Feroform bearings were approximated by bilinear curves and equation 2 was adopted for two loading regimes, By substituting Equation 2 in Equation 1 and re-writing Equation 1 for two arbitrary loading conditions within the test range,

$$
\begin{aligned}
& \mathrm{P}_{\text {in }}^{1}-\mathrm{P}_{\mathrm{misc}}-\mathrm{r} \omega\left\{\left[2 \mathrm{~F}_{13}^{1}\left(\mathrm{~m} * \mathrm{~F}_{13}^{1}+\mathrm{b}\right)\right]-\mathrm{F}_{2}^{1}\left(\mathrm{~m} * \mathrm{~F}_{2}^{1}+\mathrm{b}\right)\right\}=0, \text { for load point } 1(3) \\
& \mathrm{P}_{\text {in }}^{2}-\mathrm{P}_{\text {misc }}-\mathrm{r} \omega\left\{\left[2 \mathrm{~F}_{13}^{2}\left(\mathrm{~m} * \mathrm{~F}_{13}^{2}+\mathrm{b}\right)\right]-\mathrm{F}_{2}^{2}\left(\mathrm{~m} * \mathrm{~F}_{2}^{2}+\mathrm{b}\right)\right\}=0, \text { for load point } 2(4)
\end{aligned}
$$

Where the upper subscript stands for first and second load point/condition. Equations 3 and 4 were solved simultaneously for each bearing type and outputs ( $\mathrm{m}$ and $\mathrm{b}$ values) were substituted back into Equation 2 .

\section{Data Collection}

During each test, bearing contact surface temperature, vibrations, wear rates, and drive shaft frequency were recorded. Seals were monitored visually for any obvious water leak. At the end of 60 hours test for each bearing, power consumption of the motor drive assembly was recorded using a P3 International Corp. power monitor while loading the center bearings from no load to full load $(2640 \mathrm{~N})$ at ramping load rate ( $440 \mathrm{~N}$ per increment). Following collection of power data, bearings were dismounted and total wear was measured using internal contact gauges and micrometers as discussed in the previous section. 


\section{Results and Discussion}

\section{Bearing Wear}

Figure 7a display the total wear on the inner diameter of each bearing tested in the load-bearing (vertical) direction in sedimented water after 60 hours of testing. The PCD bearings experienced the least amount of wear among the candidate bearings. Table 3 lists the wear data collected for each bearing in sedimented and clean water. As compared to clean water test results as depicted in Figure 7b [1], all bearings showed a similar or lower amount of wear, however, a significant amount of wear on the shaft surface was observed. Also, the final clearances introduced between the polymer bearings and the shaft due to wear were significantly larger than the sizes of the sediments (Table 1) introduced in the flume. Therefore, particles of all sizes may have been able to enter the clearance spacing between the shaft and the polymer bearing, especially, past 6 to 7 hours (Figure 10) of testing.

The reason for lower wear of bearing is probably due to the contact between entrapped/impinged sediments on the bearing surface and shaft (which caused wear to shift to the shaft surface) as compared to clean water tests, in which the contact was maintained throughout the test between the bearing and the shaft surface, and therefore, no noticeable wear on shaft was observed. For PCD bearings, PCD inserts were most likely harder than the sediment particles, which minimized the particle induced wear on PCD bearings. Figures 8 and 9 show wear on the polymer bearings shaft. The higher wear on the edges of the shaft-bearing contact surface is probably due to entrapment of sediments in gaps among the snap rings, bearings, and shaft and increased edge contact pressure effects which are commonly observed in surface contact conditions [25]. This result suggests that for sedimented water, in addition to high wear resistant polymer bearings, a surface hardened or coated shaft may provide better performance.

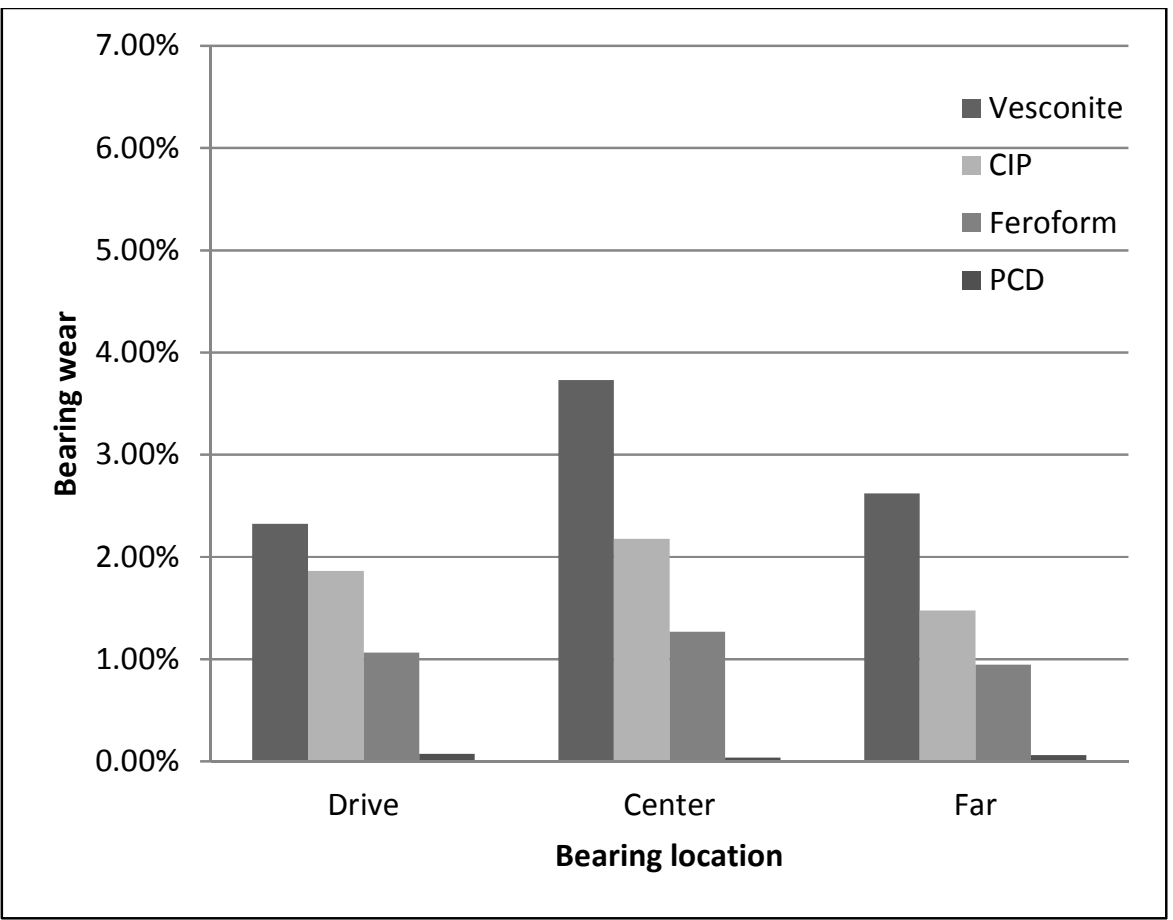




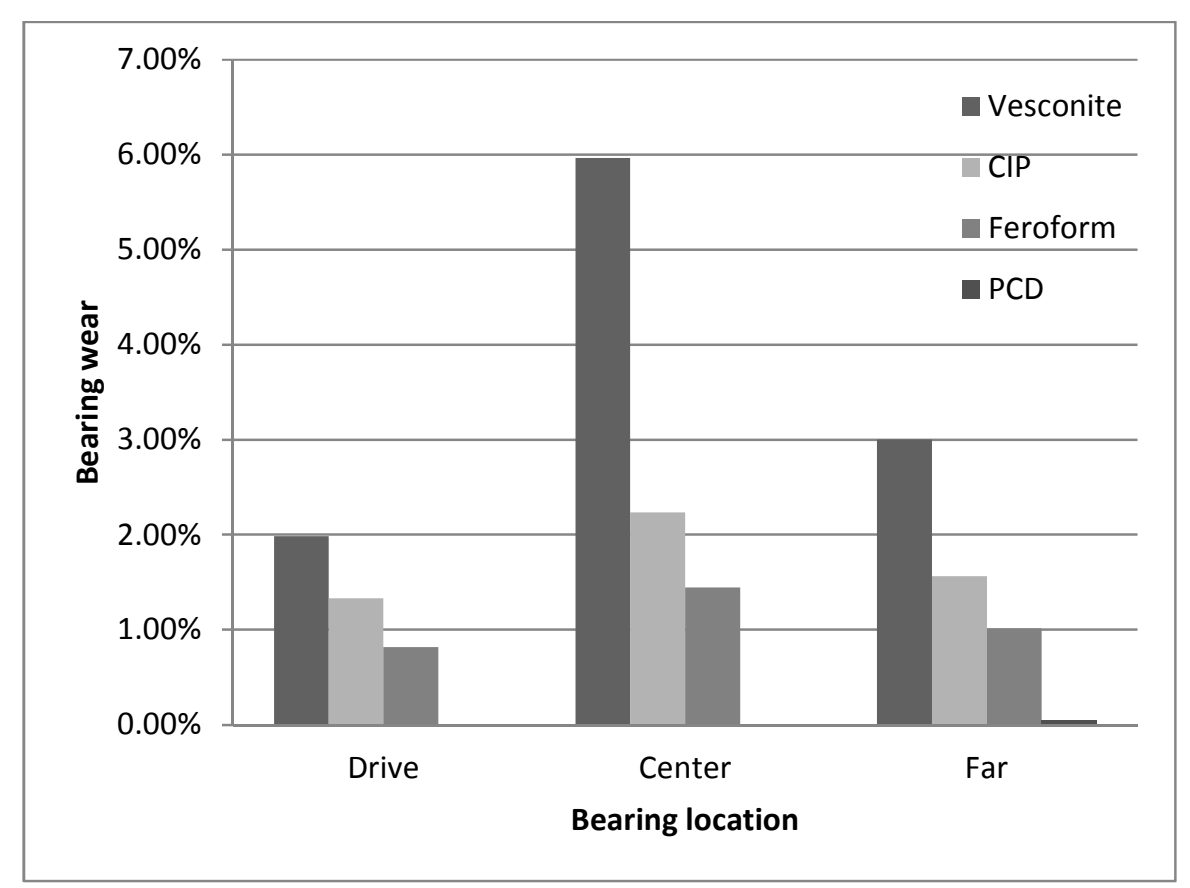

(b)

Figure 7: (a) Total wear of bearings in loading direction in sedimented water ; (b) Total wear of bearings in loading direction in clean water [1]

Table 3: Wear data of bearings in loading direction in clean and sedimented water. All dimensions are in millimeters.

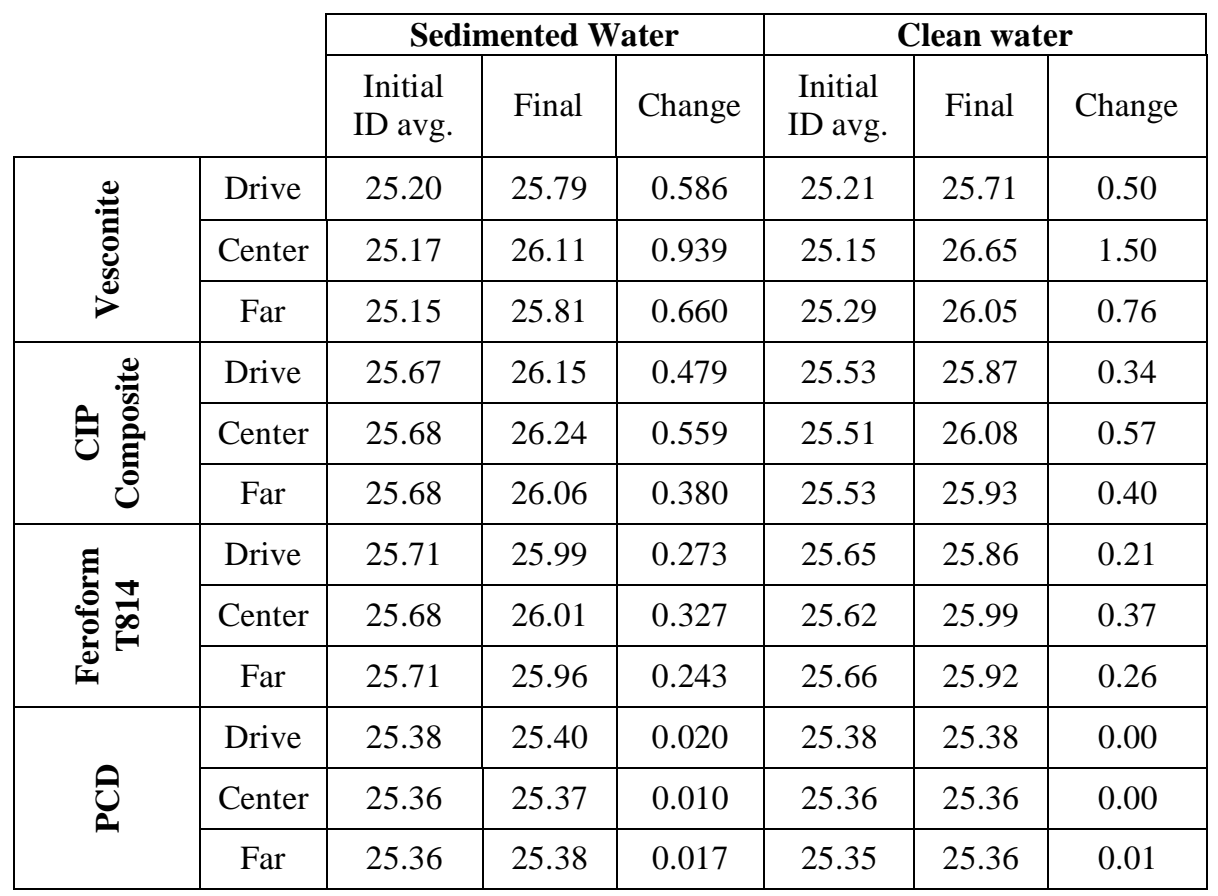




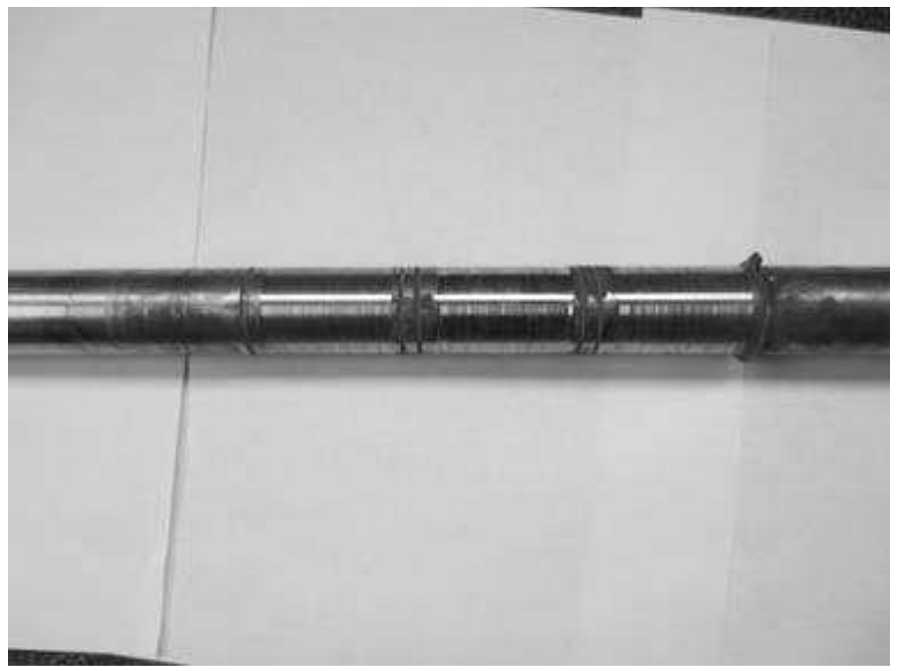

Figure 8: Shaft surface wear in sedimented water

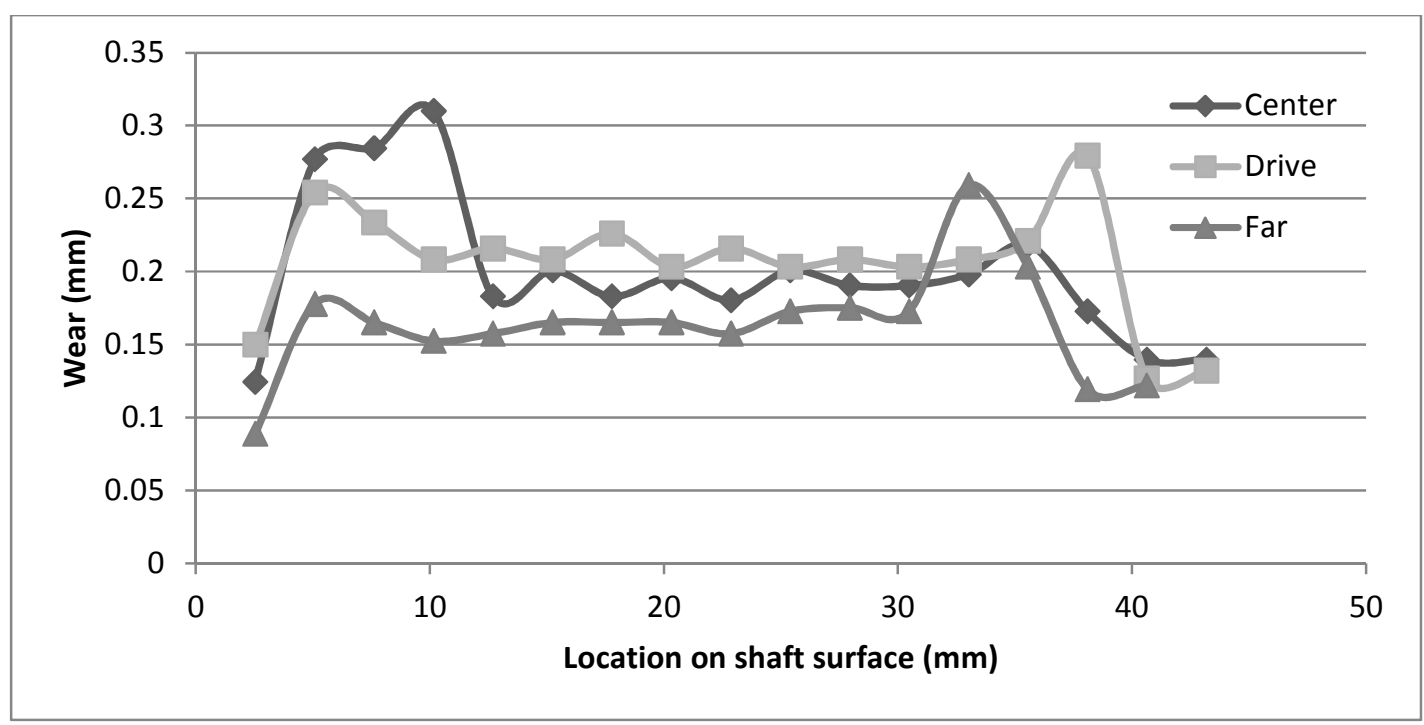

Figure 9: Shaft surface wear along the contact surface in sedimented water 


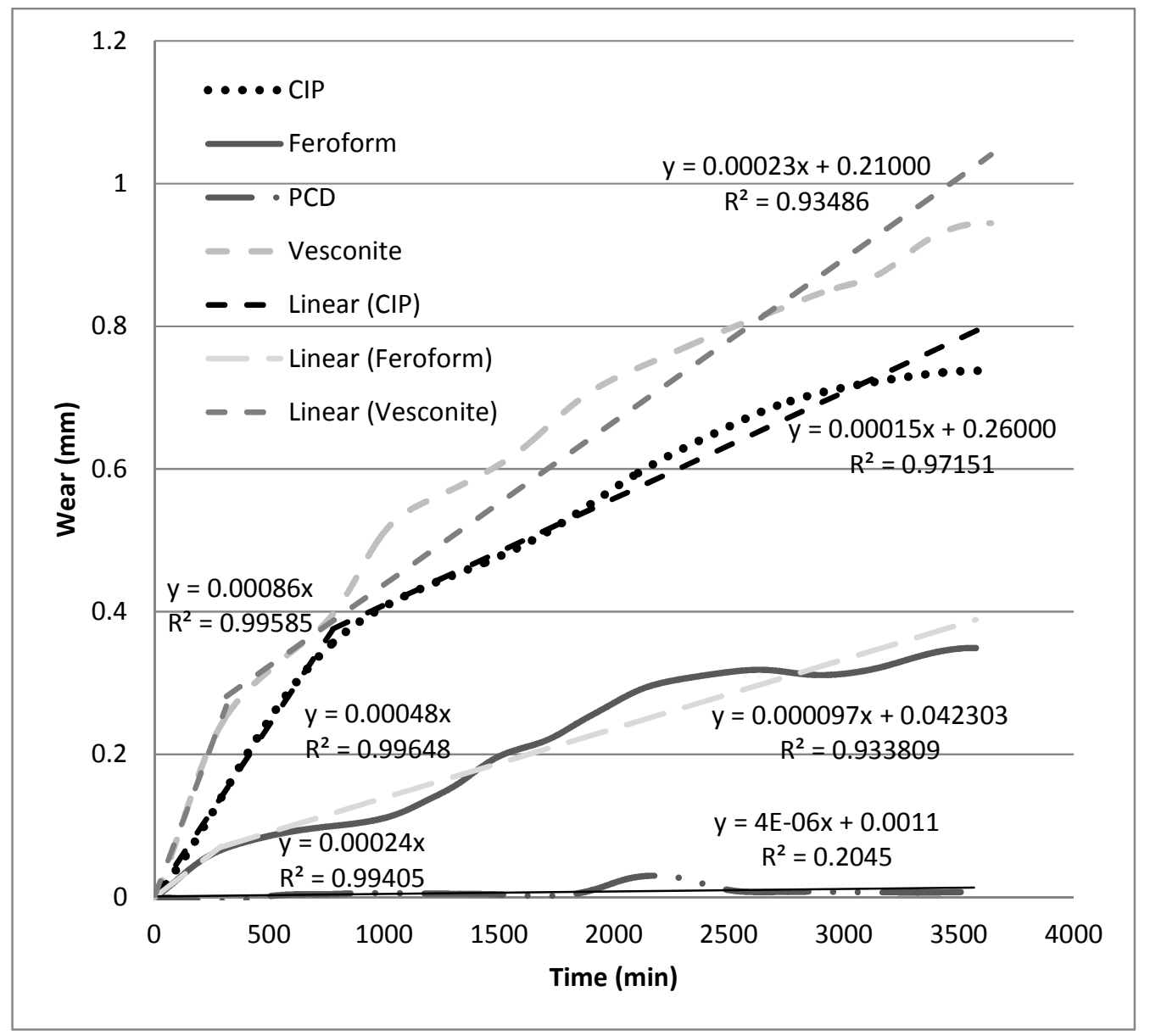

Figure 10: The center bearing (and shaft) wear along load direction with time in sedimented water

Figure 10 shows the coupled wear rate of the center bearings and shafts with time in the load direction in sedimented water. Wear rate is approximated by bilinear curves through simple regression analysis. The wear rate is initially high for polymer bearings. It is probably because bearing and shaft surfaces adjust on each other for the first few hours. Once the equilibrium in contact surface develops, wear rate reduces to a constant slope. It is evident from the LVDT data that PCD bearings, albeit having higher slope than in clean water [1], do not show any noticeable wear in sedimented water. The initial wear rates for Vesconite, CIP, and Feroform T814 bearings on a steel shaft are 0.86 $\mu \mathrm{m} / \mathrm{min}, 0.48 \mu \mathrm{m} / \mathrm{min}, 0.24 \mu \mathrm{m} / \mathrm{min}$, for approximately $5.3 \mathrm{hrs}, 13 \mathrm{hrs}, 4.8 \mathrm{hrs}$, respectively. For stabilized wear rates, the values are $0.23 \mu \mathrm{m} / \mathrm{min}, 0.15 \mu \mathrm{m} / \mathrm{min}$, and $0.097 \mu \mathrm{m} / \mathrm{min}$ for Vesconite, CIP, and Feroform T814 bearings, respectively, which reflects a wear rate reduction of approximately $73 \%, 69 \%$, and $60 \%$ as compared to respective initial wear rates.

Table 4 lists the maximum and minimum values of temperatures from the array of temperature data recorded for 60 hours of testing for each bearing type using RTDs installed in the bearing mounts on the contact surface sides. The temperatures for all bearing types were well within the operating range recommended by the respective bearing manufacturers. The temperature data for drive side PCD is unavailable due to malfunction of RTD sensor for this particular bearing during the test. However, the visual inspection of the bearing after the test showed no apparent sign of an overheated surface. Therefore, it is reasonable to assume that the temperature remained within manufacturer's recommended operable range for this bearing. 
Table 4: Maximum and minimum temperature values for bearings. All values are in Celsius $\left({ }^{0} \mathrm{C}\right)$.

\begin{tabular}{|c|c|c|c|}
\hline & & $\begin{array}{c}\text { Maximum } \\
\text { Temperature }\end{array}$ & $\begin{array}{c}\text { Minimum } \\
\text { Temperature }\end{array}$ \\
\hline \multirow{3}{*}{$\begin{array}{l}\stackrel{\mathscr{B}}{\Xi} \\
\stackrel{0}{0} \\
\stackrel{0}{0}\end{array}$} & Drive & 34.26 & 21.32 \\
\hline & Center & 31.77 & 21.20 \\
\hline & Far & 30.80 & 18.22 \\
\hline \multirow{3}{*}{ 光 } & Drive & 27.73 & 20.60 \\
\hline & Center & 27.25 & 20.56 \\
\hline & Far & 25.67 & 17.83 \\
\hline \multirow{3}{*}{ 章 } & Drive & 24.96 & 19.22 \\
\hline & Center & 24.80 & 19.12 \\
\hline & Far & 21.97 & 16.54 \\
\hline \multirow{3}{*}{ 巳 } & Drive & - & - \\
\hline & Center & 28.58 & 22.02 \\
\hline & Far & 31.66 & 24.11 \\
\hline
\end{tabular}

\section{Bearing Wear and Seal Failure Relationship}

Figures 11, 12, and 13 show the bearing-shaft wear and corresponding predicted seal life in hours for tested PV values for Vesconite, CIP, and Feroform T814, respectively, in sedimented water. The horizontal lines show the maximum tolerance limit of seals for shafts of different sizes and their intersections with wear lines reveal the numbers of hours of operations on the horizontal axis required to reach that tolerance limit, e.g., for a Vesconite bearing mounted on a $101.6 \mathrm{~mm}$ diameter shaft, a mechanical seal will have a life of $205 \mathrm{hrs}$ and $315 \mathrm{hrs}$ at PV values of $74.17 \mathrm{MPa} . \mathrm{m} / \mathrm{min}$ and 37.08 MPa.m/min, respectively, as depicted through vertical lines in Figure 11. This methodology shows that a seal leakage could be predicted at a given wear rate and PV values provided the shaft size, seal size, and seal tolerance limits are known. This is an important conclusion for hydrokinetic device manufacturers and users who are interested in setting up preventative maintenance cycles of devices to avoid any catastrophic failure of other components/systems downstream of bearing-shaft assembly. It is worth mentioning that the predicted seal failure occurs earlier in sedimented water as compared to clean water [1] for the respective bearings as listed in Table 5. Also, the wear rate data for Vesconite was unavailable as the LVDT setup was not installed during the clean water test for Vesconite [1]. Furthermore, the graphs were not generated for PCD bearings as LVDT measurements of wear were not significant enough to allow a rigorous use of this approach. The maturity and refinement of the approach presented here to an application ready state warrants further testing of seals. 


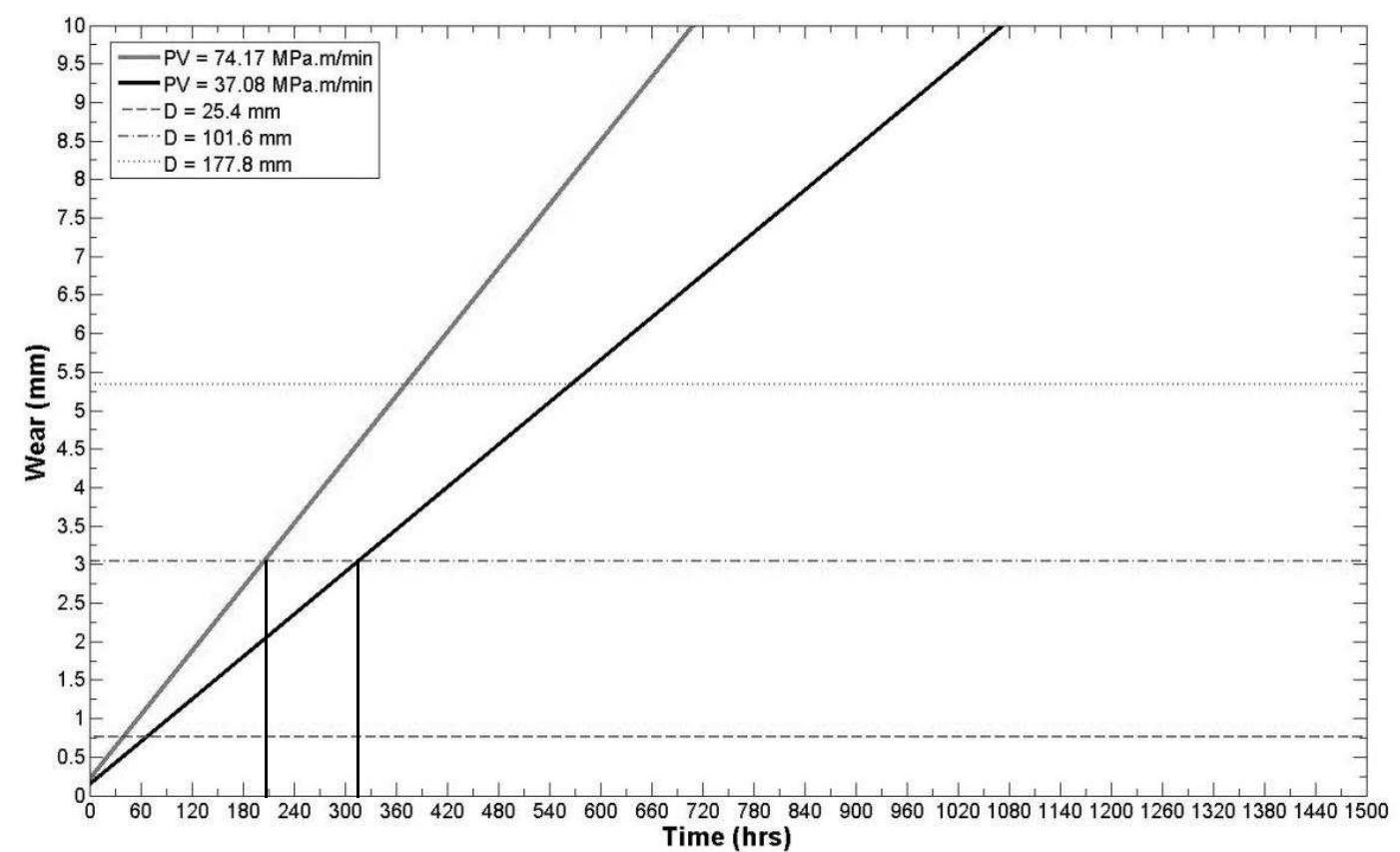
Time (hrs)

Figure 11. The wear rate of Vesconite bearings with respect to number of test hours for center ( $\mathrm{PV}=74.17 \mathrm{MPa}$. $\mathrm{m} / \mathrm{min}$ ) and side locations ( $\mathrm{PV}=37.08 \mathrm{MPa} \cdot \mathrm{m} / \mathrm{min}$ ). The horizontal lines show maximum wear mechanical seals (of appropriate size) can handle without failure when installed on shafts of $25.4 \mathrm{~mm}, 101.6 \mathrm{~mm}$, and $177.8 \mathrm{~mm}$ diameter shafts. The intercepts of vertical lines on horizontal axis show seal life of 205 and 315 hours for PV values of 74.17 MPa. $\mathrm{m} / \mathrm{min}$ and $37.08 \mathrm{MPa} . \mathrm{m} / \mathrm{min}$ for $101.6 \mathrm{~mm}$ diameter shaft, respectively.

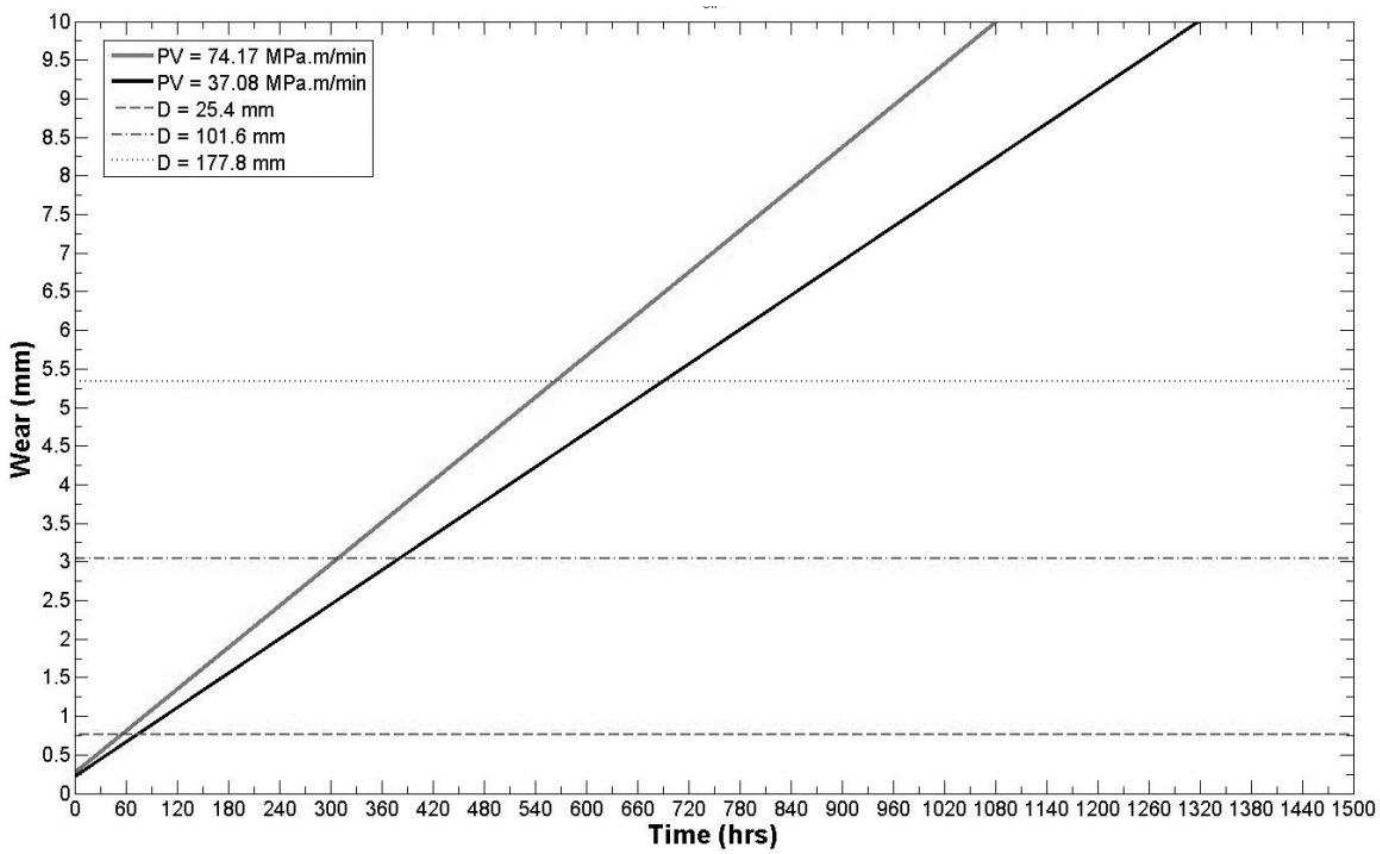

Figure 12. The wear rate of CIP bearings with respect to number of test hours for center (PV=74.17 $\mathrm{MPa}$. $\mathrm{m} / \mathrm{min})$

and side locations ( $\mathrm{PV}=37.08 \mathrm{MPa} . \mathrm{m} / \mathrm{min}$ ). The horizontal lines show maximum wear mechanical seals (of appropriate size) can handle without failure when installed on shafts of $25.4 \mathrm{~mm}, 101.6 \mathrm{~mm}$, and $177.8 \mathrm{~mm}$ diameter shafts. 


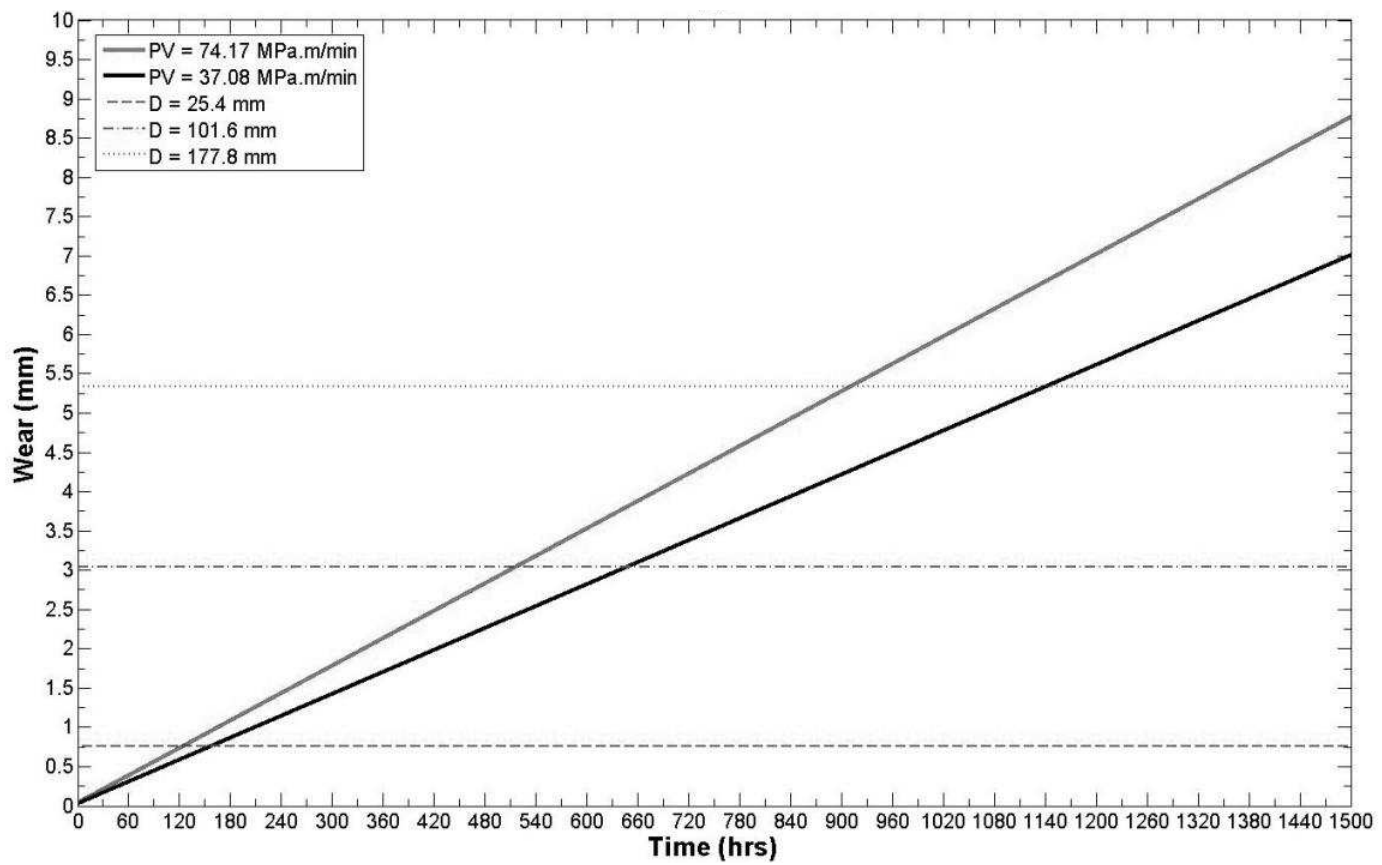

Figure 13. The wear rate of Feroform T814 bearings with respect to number of test hours for center (PV $=74.17$ $\mathrm{MPa} . \mathrm{m} / \mathrm{min}$ ) and side locations (PV=37.08 MPa.m/min). The horizontal lines show maximum wear mechanical seals (of appropriate size) can handle without failure when installed on shafts of $25.4 \mathrm{~mm}, 101.6 \mathrm{~mm}$, and $177.8 \mathrm{~mm}$ diameter shafts.

Table 5: Expected seal life for each bearing type. All values are in hours.

Bearing Frictional Resistance

Figure 14a shows the COF of all bearings with increasing load in the sedimented water condition. PCD bearings showed the least amount of frictional resistance with almost invariant value along the applied load. The highest values of COF were noted for Vesconite for loads under $1850 \mathrm{~N}$. Past that point, a steep rise in COF was observed for both Feroform T814 and CIP bearings, with higher slope for Feroform T814. This is probably due to the 
entrapment of sediments in the shallow pockets observed on the composite bearing surfaces of CIP and Feroform T814. At full load, the Feroform bearing showed the highest value of COF followed by Vesconite, CIP, and PCD bearings, respectively. It may be noted that values of COF in sedimented water are relatively lower than the values in clean water as shown in Figure 14b [1]. This may be due to the rolling action of sedimented particles in between the bearing and shaft surface.

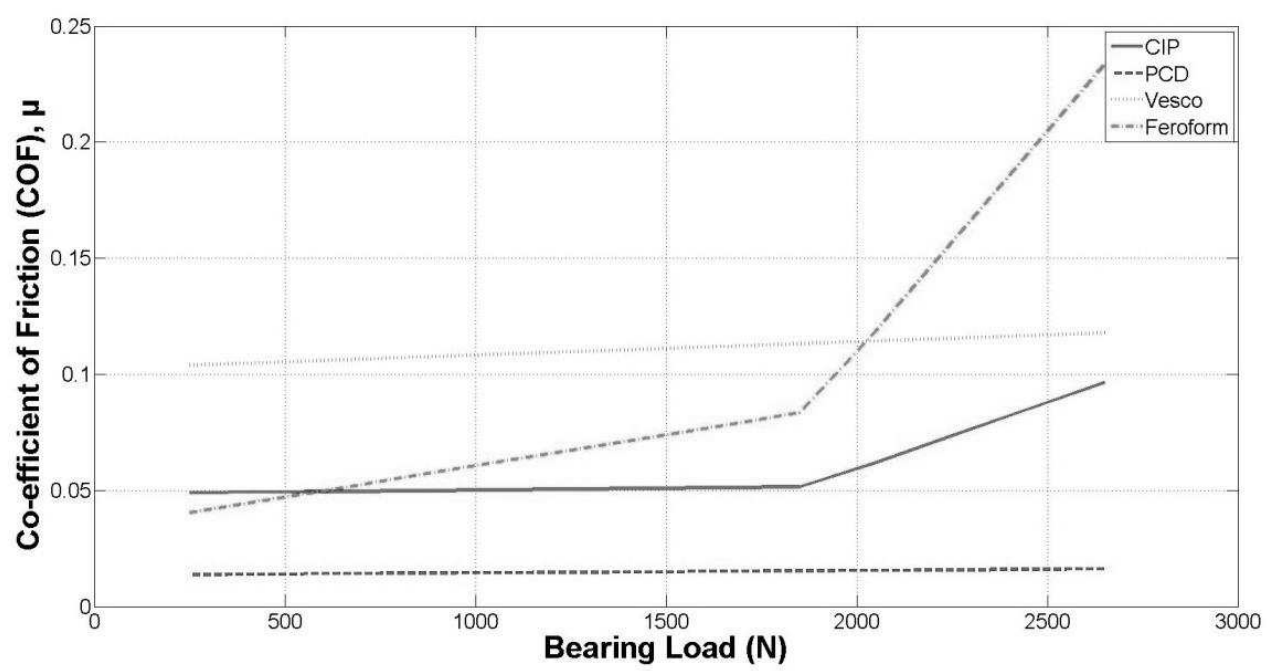

(a)

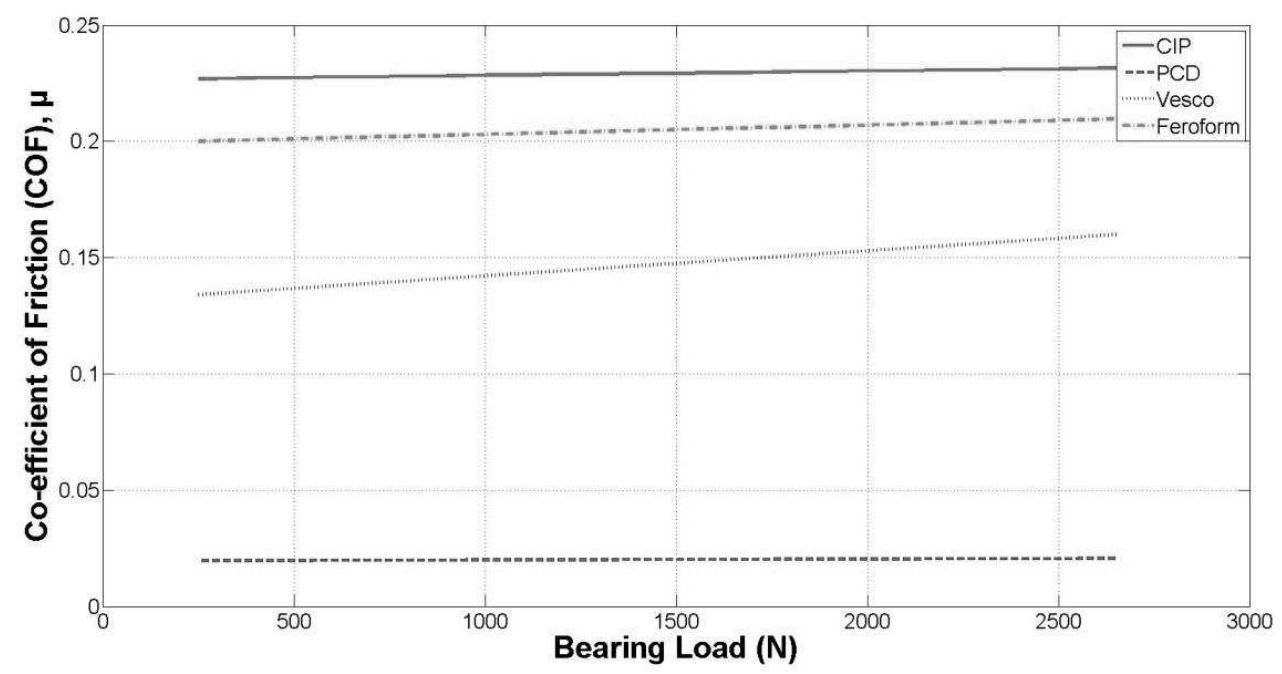

Figure 14. (a) Coefficient of friction of each bearing with load in sedimented water (b) Coefficient of friction of each bearing with load in clean water [1]

\section{Cost-effectiveness}

The PCD bearings used in present study were approximately sixty times more expensive than the polymer based bearings. However, cost associated with a high frequency preventive maintenance cycle on an average size river hydrokinetic device (15 to $25 \mathrm{KW}$ ) and tidal hydrokinetic device (100 to $150 \mathrm{KW}$ ) due to short seal life (as shown in Table 4) will most likely be high and may prohibit the use of polymer based bearings. Based on hydrokinetic device size, seal-assembly size and complexity, operational depth and generator size, detailed economic and value analyses 
are recommended to make cost-effective choices in selecting polymer or non-polymer based bearings presented in this study.

\section{Conclusions}

In the present study, the wear and frictional resistance of four bearing types namely Vesconite, CIP, Feroform T814, and PCD commonly used in hydrokinetic devices were determined by testing the bearings in submerged sedimented flowing water environment under loading conditions similar to the field conditions. In agreement with clean water test data [1], the results in present study reveal that PCD bearings have highest wear resistance and lowest friction resistance among the tested bearings. In addition, a higher wear rate was observed for polymer based bearings, which may be attributed to adjustment of bearing-shaft contact surface. In contrast to clean water test [1], a significant amount of scoring was observed on the shaft, which suggests that a surface hardened shaft might be needed, in addition to high wear resistant polymer bearings, to improve the bearing-seal assembly performance life in harsh sedimented water conditions.

\section{Acknowledgements}

This work is supported by the United States Department of Energy (DOE) fund (DE-EE0003631), the Ocean Renewable Power Company (ORPC) match fund, the Office of Research of the University of Alaska Anchorage (UAA) match fund, and Ohio University (OU) Research Fund. Authors would like to extend their gratitude to US Synthetics, Columbia Industrial Products, and TENMAT Ltd. for providing test bearings. Authors would also like to thank anonymous referees for providing useful, constructive, and insightful feedback that resulted in a significant improvement of the original manuscript.

\section{References}

1. Bromaghin, A., Ali, M., Ravens, T., Petersen, T., and Hoffman, J., "Experimental study of abrasion characteristics for critical sliding components for use in hydrokinetic devices." Renewable Energy 66 (2014): 205-214.

2. Crosset, Kristen M. Population trends along the coastal United States: 1980-2008. National Ocean Service, 2005.

3. Colgan, Charles S. "The changing ocean and coastal economy of the United States: A briefing paper for governors." Edmund S. Muskie School of Public Service, University of Southern Maine. Presentation prepared for National Governors Association Conference. 2004.

4. Vermaark, H. J., Kusakana, K., and Koko, S.P., "Status of micro-hydrokinetic river technology in rural applications: A review of literature." Renewable and Sustainable Energy Reviews 29 (2014): 625-633

5. Kaygusuz, K., Güney, M. S., "Hydrokinetic energy conversion systems: A technology status review." Renewable and Sustainable Energy Reviews 14.9 (2010): 2996-3004

6. Chen, L., Ponta, F. L., and Lago, L., I., "Advances and trends in hydrokinetic turbine systems.” Energy for Sustainable Development 14.4 (2010): 287-296

7. Shields, Mark A., Woolf, David, K., Grist, Eric, P. M., Kerr, Sandy, A., Jackson, Angus, Harris, Robert, E., et al. "Marine renewable energy: The ecological implications of altering the hydrodynamics of the marine environment." Ocean \& Coastal Management 54.1 (2011): 2-9.

8. Chris, Fred, Eider, Andonegi, Jochen Depestele, Adrian, Judd, Dominic Rihan, Stuart, Rogers, I., et al. "The environmental interactions of tidal and wave energy generation devices." Environmental Impact Assessment Review 32.1 (2012): 133-139.

9. Lin, Lan, and Haitao Yu. "Offshore wave energy generation devices: Impacts on ocean bio-environment." Acta Ecologica Sinica 32.3 (2012): 117-122.

10. Ahmadian, Reza, Roger Falconer, and Bettina Bockelmann-Evans. "Far-field modelling of the hydroenvironmental impact of tidal stream turbines." Renewable Energy 38.1 (2012): 107-116.

11. Draper, S., Houlsby, G. T., Oldfield, M. L. G., and Borthwick, A. G. L., "Modelling tidal energy extraction in a depth-averaged coastal domain." Renewable Power Generation, IET 4.6 (2010): 545-554.

12. Cruz, João, ed. Ocean wave energy: current status and future prespectives. Springer, 2008.

13. Hinrichsen, Don. Coastal waters of the world: trends, threats, and strategies. Island Press, 1999. 
14. Kadiri, Margaret, Ahmadian, Reza, Bockelmann, Bettina, E., Rauen, William, and Falconer, Roger, "A review of the potential water quality impacts of tidal renewable energy systems." Renewable and Sustainable Energy Reviews (2011).

15. Harrison, Gareth P., and A. Robin Wallace. "Climate sensitivity of marine energy." Renewable Energy 30.12 (2005): 1801-1817.

16. Langton, R., I. M. Davies, and B. E. Scott. "Seabird conservation and tidal stream and wave power generation: Information needs for predicting and managing potential impacts." Marine Policy 35.5 (2011): 623-630.

17. Meicke, Stephen, and Robert Paasch. "Seawater lubricated polymer journal bearings for use in wave energy converters." Renewable Energy 39.1 (2012): 463-470.

18. Hirani, Harish, and Manish Verma. "Tribological study of elastomeric bearings for marine propeller shaft system." Tribology International 42.2 (2009): 378-390.

19. Wood, Robert J.K., Bahaj, AbuBakr, S., Turnock, Stephen, R., Wang, Ling, and Evans, Martin, "Tribological design constraints of marine renewable energy systems." Philosophical Transactions of the Royal Society A: Mathematical, Physical and Engineering Sciences 368.1929 (2010): 4807-4827.

20. Chen, Beibei, Jianzhang Wang, and Fengyuan Yan. "Friction and wear behaviors of several polymers sliding against GCr15 and 316 steel under the lubrication of sea water." Tribology Letters 42.1 (2011): 1725 .

21. Schuster, F.P. "Water and sediment quality in the Yukon River Basin, Alaska, during water year 2004." USGS Study, 2006.

22. Kyle, E.R., Brabets, P. T. "Water temperature of streams in the Cook Inlet basin, Alaska, and implications of climate change." USGS Study, 2001.

23. Brabets, P. T., Wang B., Meade R.H. "Environmental and hydrologic overview of the Yukon river basin, Alaska and Canada." USGS Study, 2000.

24. Avraham, Harnoy. "Bearing design in machinery: engineering tribology and lubrication." Marcel Dekker Inc., 2003

25. Ali, M., Shakoor, M., Flugrad, D., Qamhiyah, A. "Contact stresses in conical rollers.” Journal of Strain Analysis for Engineering Design 42.8 (2007): 595-604. 